\title{
CONTRATO SOCIAL ENTRE MUJERES Y HOMBRES*
}

\author{
Rosario VALPUESTA FERNÁNDEZ \\ CATEDRÁtICA DE DERECHO CIVIL \\ UNIVERSIDAD PABLO OLAVIDE, SEVILLA
}

\section{Acerca del contrato social}

En esta intervención se pretende reflexionar acerca de una propuesta que ha ido ganando aceptación en los últimos tiempos: nos referimos al contrato social mujeres y hombres ${ }^{\mathrm{I}}$. Así, evocando el contrato social formulado por Rousseau como fundamento para la construcción del Estado, se pretende una nueva reedición del mismo. Un contrato que, se dice, se ha de celebrar entre los dos géneros, y mediante el cual deben fijarse las condiciones para una nueva convivencia social en la que participen por igual los ciudadanos y las ciudadanas.

La propuesta de Rousseau es una elaboración teórica que se enmarca en el pensamiento político desarrollado en el siglo XVIII, y que suministra las bases ideológicas y conceptuales de la Revolución Francesa así como del nuevo orden social que se instaura tras el triunfo de la misma ${ }^{2}$. Un pensamiento que hunde sus raíces en el humanismo para construir desde la lógica de la razón un modelo de organización política asentado en la soberanía del pueblo. Estamos pues ante una propuesta que se desenvuelve en el plano de las ideas más que en el de la realidad. Una propuesta en la que se diseña el proceso mediante el cual se ha de pasar del «estado de naturaleza» al de sociedad organizada; y cuyo tránsito ha de producirse mediante el contrato social de todos los hombres para constituirse en pueblo del que emana el poder político.

\footnotetext{
" Esta contribución ha sido previamente publicada en la Revista Trimestral de Direito Civil, Río de Janeiro, outubro/dezembro, 2006, págs. II9-I48. Forma parte de las ideas expuestas por la autora en la ponencia desarrollada en el VIII Seminario Permanente de Derecho Privado, Universidad de La Rioja, («Principio de igualdad, feminismo y Derecho») y, dada la vigencia de su contenido, se publica con autorización de la Dra. Valpuesta Fernández.

' Desde la Asociación de mujeres progresistas se ha defendido esta propuesta plasmada en una acción política y en un texto, http://humano.ya.com/ampvictoriakent/Contrato.htm.

2 Sobre las reivindicaciones feministas en la Revolución francesa, Celia Amorós, Tiempo de feminismo, Madrid I997, págs. I63 ss.

${ }^{3}$ Este pensamiento ha sido denominado como el Discurso de la modernidad por Habermas, El discurso filosófico de la modernidad, Madrid, I98I.
} 
Rousseau: «Supongo a los hombres llegados a un punto en que los obstáculos que se oponen a su conservación en el estado natural vencen con su resistencia a las fuerzas que cada individuo puede emplear para mantenerse en ese estado. Entonces, ese estado primitivo no puede ya subsistir, y el género humano perecería si no cambiase su manera de ser.

Ahora bien, como los hombres no pueden engendrar nuevas fuerzas, sino solamente aunar y dirigir las que existen, no les queda otro remedio, para subsistir, que formar por agregación una suma de fuerzas que pueda superar la resistencia, ponerlas en juego mediante un solo móvil y hacerlas actuar de consuno.» ${ }^{4}$

Con independencia del contenido concreto de la obra en la que desarrolla su pensamiento, la expresión contrato social y la idea básica que expresa se sublima hasta el punto de constituir una referencia imprescindible en la explicación y justificación del nuevo orden político que se implanta tras la Revolución Francesa; se convierte en la feliz síntesis del sistema democrático que se legitima en la decisión libre de los hombres para gobernarse a sí mismos 5 .

En el origen del mismo están la formulación política y jurídica de la libertad y la igualdad, en las que se resumen el conjunto de los nuevos valores con los que se quiere identificar el cambio político; una libertad y una igualdad que se consideran consustanciales a la naturaleza humana; tienen, pues, un alcance universal ${ }^{6}$ pero, como veremos, una dimensión esencialmente masculina?

Rousseau: «Si se indaga en qué consiste precisamente el mayor bien de todos, el cual debe constituir el fin de todo sistema de legislación, se encontrará que se reduce a dos objetos principales: la libertad y la igualdad. La libertad porque toda dependencia particular es fuerza que se resta al cuerpo del Estado; la igualdad, porque la libertad no puede subsistir sin ella.» ${ }^{8}$

Ocurre, sin embargo, que estos derechos se contemplan en un plano teórico, desconectados de la situación real de la sociedad a la que se dirigen: la igualdad y la libertad son exclusivamente formales, en el convencimiento de que la dinámica de las relaciones sociales, lejos de cualquier intervencionismo estatal, permitirá a cada uno la realización de sus propios derechos. Además, estos derechos se definen frente al poder político, que era el único, se pensaba, que podía vulnerarlos; y se diseña un Estado mínimo, escasamente interventor, para que las personas, mejores conocedoras de sus intereses, sean las que ejerzan su libertad desde la igualdad formalmente declarada. En este orden de cosas se

\footnotetext{
${ }^{4}$ El contrato social, Madrid, 2004, Pág. 43.
}

${ }^{5}$ En el pensamiento de Rousseau, la mujer no es sujeto del contrato social ni participa en la constitución de la voluntad general, Cristina Molina, «Genealogía de la vindicación», Elena Beltrán y Virginia Maquieira (eds.) Feminismos. Debates teóricos contemporáneos, Madrid, 200I, págs. 20 ss.

${ }^{6} \mathrm{Al}$ respecto afirma Geneviève Fraisse, que cuando se impone la lógica universalizadora de la democracia, la excepción constituirá un problema, porque, de acuerdo con la misma, no es asimilable a título de tal. Musa de la Razón, Madrid I99I, págs. II5 SS

${ }^{7}$ Para Carole Pateman,el contrato original constituye, a la vez, la libertad y la dominación. La libertad de los varones y la sujeción de las mujeres se crea a través del contrato original, y el carácter de la libertad civil no se puede entender sin la mitad despreciada de la historia, lo cual revela cómo el derecho patriarcal de los hombres sobre las mujeres se establece a partir del contrato, El contrato sexual, Madrid, I995, págs. Io y II. Por su parte, afirma Victoria Camps: «Kant, con su universalismo moral a cuestas, no tiene reparos en afirmar que las mujeres solo son capaces de entender el lenguaje de la belleza, pero son negadas para la ley y para la justicia. Rousseau pone en el centro de su democracia la voluntad general, pero diseña una forma de educar para hombres y otra para mujeres porque los unos y los otros no están hechos para lo mismo», El siglo de las mujeres, Madrid I998, pág. 30. Por su parte, Cinta Canterla afirma que «Debido precisamente a la pretendida incapacidad (entendida más adelante como jurídica) de las mujeres para haber llevado a cabo el contrato social originario, se la excluirá del corpus político, argumentando que la mujer no pudo tomar racionalmente la decisión moral que origina el derecho de ciudadanía, deteniéndola así a medio camino entre el estado de naturaleza y el de ciudadanía», «Lenguaje y poder en el siglo XVIII: la voz pública y la polémica de los sexos», Debate y Perspectivas, 3, 2003, pág. I76.

\footnotetext{
${ }^{8}$ El contrato social cit. pág. 79 .
} 
diseña un único sujeto de derechos con el que se quería superar la diversidad social y jurídica del antiguo régimen ${ }^{9}$. Estamos entonces en el Derecho de la uniformidad, que se manifiesta en la proclamación de un solo ciudadano ${ }^{\mathrm{IO}}$, de una sola propiedad y de un único modelo de familia.

\section{La igualdad burguesa}

Bajo este paraguas formal de la Declaración de los Derechos del Hombre y del Ciudadano ${ }^{\text {II }}$, lo que realmente se instaura con el cambio político es el Estado liberal burgués cuyo único patrón, el ciudadano, resulta ser el hombre burgués blanco, que desde su primacía social asume el desarrollo de los principios expuestos. Y así, desde su posición, ordena el conjunto de las relaciones jurídicas y sociales sin ninguna traba por parte de unos poderes públicos desvinculados de un compromiso por la igualdad afectiva.

Unas relaciones que tienen un determinado cariz en lo que respecta a las mujeres, pues en esta época se elabora todo un ideario en torno a la misma, que tiene como consecuencia su confinamiento en el hogar familiar y su exclusión del ámbito productivo en el que hasta entonces había participado. En efecto, se establece una neta separación entre el espacio público y el privado ${ }^{\mathrm{r} 2}$ : el primero reservado a los hombres, y el segundo destinado a las mujeres, elaborando para este último las nociones de lo doméstico o de la domesticidad, en las que se quiere resumir el mundo pequeño de lo femenino, y que sin embargo mantiene una relación de dependencia y subordinación al varón, además de su escaso reconocimiento por parte de éste. Se elaboran asimismo nociones como la de corrección y respetabilidad que reflejan el ideal burgués acerca de la familia, unas nociones que se aplican sobre todo a las mujeres, para las que se establecen un conjunto de reglas que rigen su comportamiento y que giran en torno a las funciones que le son asignadas: el cuidado de los hijos y las tareas de la casa, todo ello bajo la autoridad del padre o del marido. Y esta concepción de lo que debe ser la vida familiar influye en el diseño de la vivienda, que se separa del lugar del trabajo para preservar su privacidad, y también en la misma ordenación de las ciudades que responde al pensamiento burgués de ámbitos diferenciados.

Pero, sobre todo, se produce un hecho notable que marcará el destino de las mujeres: el rechazo por parte de la burguesía de la mujer trabajadora, al considerar esta actividad incompatible con el papel que le ha sido asignado en la familia, con lo que termina por imponerse el ideario de la diferencia con una nitidez que no había tenido en otro momento histórico. Como nos indica Goody ${ }^{\text {I3 }}$ : «La segunda mitad del siglo XIX conoció la gradual expansión del rechazo a las 'esposas trabajadoras'; un sentimiento que, presente antes en la aristocracia, fue adoptado por la alta burguesía a comienzos del siglo XVIII y más tarde por los elementos más altos de la clase trabajadora... Esto condujo a

\footnotetext{
${ }^{9}$ En el antiguo régimen, «Grandes damas, reinas o señoras territoriales tenían privilegios de los que muchos varones estaban excluidos. La jerarquía en razón del nacimiento interrumpe la continuidad genérica o, la menos, la diluye.» Amelia Valcarcel, La política de las mujeres, Madrid I997, pág. 25.

${ }^{10}$ Interesante reflexión sobre la construcción del sujeto en Celia Amorós, Tiempo de feminismo, Madrid I997, págs. I9 ss.

" «La Declaración de I789 eleva al sujeto (a sus derechos) a elemento definidor del concepto de Constitución en el conocido artículo i 6 en el que simultáneamente se establece la división entre el ámbito privado (el de los derechos) y el público (los poderes del Estado), el de la sociedad y el del Estado, el de la diferencia y el de la igualdad, si bien este último (el de la igualdad en el Estado) sólo referido a los ciudadanos, no a todos los hombres», Carlos de Cabo Martín, «El sujeto y sus derechos...», pág. I2I.

${ }^{12}$ Sobre el tema, Carole Pateman, «Criticas feministas a la dicotomía público/privado», en Carme Castell (compiladora), Perspectivas feministas en la teoría política, Barcelona, I996, págs. 3I Ss.

${ }^{13}$ La familia europea, Barcelona 2001, pág. 165.
} 
poner el acento en la 'maternidad moral', en la que el cuidado de los hijos y las tareas de la casa eran la función más valiosa y la que más realizaban las mujeres».

Y este ideal burgués se refleja en los textos legales, en el imaginario colectivo, en la práctica social, hasta llegar a ser asumido por la clase trabajadora, en la medida que sus condiciones materiales se lo permitían, para consolidarse definitivamente como el modelo a seguir ${ }^{\mathrm{I}}$. Y es que las precarias condiciones en las que se desarrolla la actividad laboral de la mujer de la clase trabajadora propician que vean en el hogar familiar un destino que les libere de su explotación ${ }^{15}$.

Pero la diferencia no es aquí diversidad: es desigualdad. Desde la débil posición en la que se coloca a la mujer resulta fácil justificar su sumisión al varón ${ }^{\text {16; }}$ no plantea problemas reconocer su menor capacidad para las actividades públicas; resulta incluso conveniente que se le proteja mediante la autoridad del padre o del marido... Y esta desigualdad que se consagra en los textos legales parece que no inquieta a los postulados en los que se asentaba el Estado liberal: la libertad y la igualdad ${ }^{17}$.

Rousseau: «Por cualquier lado que nos remontemos al principio, llegamos siempre a la misma conclusión: que el pacto social establece entre los ciudadanos tal igualdad que todos se obligan en las mismas condiciones y deben gozar todos de los mismos derechos» ${ }^{18}$.

\section{La larga lucha por la igualdad}

A pesar de las formulaciones jurídicas, del peso de los convencionalismos sociales, de su escasa libertad y su precario protagonismo social, las mujeres inician el difícil camino de la conquista de su igualdad ${ }^{19}$. Organizándose en torno a los movimientos feministas que llegan a adquirir incluso una dimensión internacional, las mujeres europeas y americanas plantean sus reivindicaciones básicas, que cifran en un primer momento en el derecho a la

${ }^{14}$ A medida que fue avanzando el siglo XIX, como pone de manifiesto Guttormsson, «los conceptos de 'respetabilidad' entre las capas superiores de la clase trabajadora fueron modelados, cada vez en mayor medida por la ideología doméstica», «Las relaciones paternofiliares», La vida familiar desde la revolución francesa hasta la primera guerra mundial, 1789-1913, Barcelona 2002, pág. 395.

${ }^{15}$ «Feminidad e infancia se nos muestran de este modo como dos reductos estamentales de la modernidad, según los cuales se configuró el espacio privado de la familia...El carácter de inferioridad estamental de estos colectivos se pone de manifiesto en el hecho de que, cuando la lógica de la explotación de la primera fase del capitalismo se ponga en marcha, los miembros desfavorecidos de estos grupos segregados con un significativo plus con respecto a los varones adultos de esa misma clase», Celia Amorós, Tiempo de feminismo, cit. pág. 279.

${ }^{16}$ En Gran Bretaña la posibilidad de que las mujeres casadas pudieran celebrar contratos no fue reconocida hasta I935.

${ }^{17}$ Como expresa Amelia Valcarcel: «Así las cosas, sucedió que el primitivo pensamiento de la ciudadanía, que se expresó tanto en las codificaciones legales post-revolucionarias como en la filosofía, se edificó a costa de los derechos omitidos del colectivo de mujeres. A fin de no contemplar la injusticia política derivada del sexo, el romanticismo argumentó que esa desigualdad era 'natural', frente a los que con anterioridad habían sostenido que era ética y política», La política de las mujeres, Madrid I997, pág. 25.

${ }^{18}$ El contrato social cit. pág. 60.

${ }^{19}$ Con anterioridad existen ya escritos que se pronuncian sobre la mujer y su papel en la sociedad, entre los que cabe resaltar la obra de Fanny Burnier de la Mongallaz De la influencia de las mujeres en las costumbres y la suerte de las naciones, que responde a lo que se ha denominado la primera ola del feminismo, en la que Amelia Valcarcel sitúa a Polain de la Barre, con De la igualdad de los sexos. De la educación de las damas, y Mary Willstenocraft, con Vindicación, en la introducción a El debate sobre le voto femenino en la Constitución de 1931, Madrid 200I. Un estudio en profundidad sobre la obra de Polain de Barre lo hace Celia Amorós, Tiempo de feminismo, cit. págs. Io9 ss. Por su parte Cinta Canterla nos revela la presencia del feminismo en el discurso político que se refleja en la prensa del siglo XVIII, «Lenguaje y poder en el siglo XVIII: la voz pública y la polémica de los sexos», Debate y Perspectivas, 3, 2003, págs. I73 ss. 
educación y al ejercicio profesional, a las que le acompañarán el derecho al sufragio ${ }^{20}$. Estas movilizaciones las protagonizan esencialmente mujeres burguesas que quieren acceder a los ámbitos de los hombres; pero también se movilizaron las asalariadas, atrapadas en las fábricas, que demandan más sueldos y mejores condiciones en el trabajo y, en muchos casos, como se ha dicho, que se las libere de la explotación a la que está sometidas; una lucha, ésta de las mujeres trabajadoras, que hay que enmarcar en el movimiento obrero ${ }^{2 \mathrm{I}}$.

Se inicia pues un largo camino realmente complejo y contradictorio como son los siglos XIX y XX en Europa. Unos siglos marcados por grandes transformaciones políticas, económicas y sociales en los que, a impulsos de movimientos sociales, de ideologías muy dispares, de conflictos internacionales bien cruentos, se modela un pensamiento que termina por implantarse en los Estados democráticos tras la Segunda Guerra Mundial. Durante todos estos años, y como enseguida veremos, la mujer transita un lento y tortuoso recorrido hasta llegar al reconocimiento de su igualdad respecto al hombre. Nos encontramos pues que las distintas constituciones proclaman expresamente la igualdad entre los hombres y mujeres, vetando toda discriminación y, lo que es más importante, que tal declaración tiene eficacia jurídica, es decir, que se imponen al resto del ordenamiento para disipar todo rastro de discriminación que pudiera existir por razón del sexo $^{22}$.

Rousseau: «Al recobrar su libertad por el mismo derecho con que le fue arrebatada, o tiene razón para reivindicarla, o no la tenían para quitársela. Pero el orden social es un derecho sagrado que sirve de base a todos los demás. No obstante, este derecho no procede de la naturaleza; luego se funda en convenciones. Se trata de saber cuales son estas convenciones». ${ }^{23}$

La igualdad formal, aquella que se proclama en los textos legales, se va consiguiendo a medida que se impone el cambio constitucional, pero ésta es insuficiente para transformar una sociedad todavía injusta que coloca a las mujeres en una clara situación de desventaja ${ }^{24}$. Es necesario entonces una mayor implicación con la igualdad real.

\footnotetext{
${ }^{20}$ Un hito lo marca el Manifiesto de Séneca de i848. Fue la exclusión de las delegadas femeninas en i840 de la Convención Mundial contra la Esclavitud, celebrada en Londres, lo que impulsó a organizar la Primera Convención de los Derechos de las Mujeres, en Séneca Falls, Nueva York, i848, Bonny S. Anderson y Judith P. Zinsser, Historia de las mujeres: Una historia propia, vol. II, Traducción Beatriz Villacañas, Barcelona, I99I, pág. 406.

${ }^{21}$ La relación entre feminismo y clase hay que enmarcarla en el debate entre feministas y marxismo. Al respecto Catharine A. McKinnon afirma que «En el caso de las mujeres burguesas, limitar el análisis de la situación de la mujer a su relación con el capitalismo y limitar este análisis a su relación con el capitalismo a través de los hombres, es ver solo un aspecto indirecto. No hacerlo en el caso de la mujer proletaria es pasar por alto su aspecto indirecto. En ambos casos, definir la situación de las mujeres sólo en términos de clase es pasar por alto enteramente su situación como mujeres a través de las relaciones con los hombres, que es una situación relacional definitoria que comparten, incluso aunque difieran, los hombres a través de los cuales la adquieren», Hacia una teoría feminista del Estado, Madrid 1995, págs. 23 ss.

${ }^{22}$ En el plano internacional se deben tener en cuenta, la Declaración Universal de los Derechos Humanos, de I948, el Pacto Internacional de Derechos Civiles y Políticos y el Pacto Internacional de Derechos Económicos, Sociales y Culturales, ambos de I966. En I979 se aprobó igualmente por NNUU la Convención contra toda forma de discriminación contra la mujer.

${ }^{23}$ El contrato social cit. pág. 34: afirmación que la hace respecto del pueblo.

${ }^{24}$ Las transformaciones que se producen en los ordenamientos jurídicos a partir de la segunda guerra mundial se deben sin duda a los movimientos feministas de los años sesenta, sobre el tema Amelia Valcarcel, $L a$ política de las mujeres cit. págs. 93 ss. Una exposición de estos cambios normativos en España, Amparo Rubiales Torrejón, Evolución de la situación jurídica de la mujer en España, Instituto Andaluz de la mujer, Granada 2003, también, Ruth Rubio Marín (coordinadora), Mujer e igualdad: la norma y su aplicación (aspectos constitucionales, penales $y$ civiles, 3 tomos, Instituto Andaluz de la Mujer, Sevilla I999. Es muy interesante la exposición sobre la aplicación por parte del Tribunal Federal Alemán del principio de igualdad de la mujer y el varón y su incidencia en las relaciones familiares que hace Blanca Rodríguez Ruiz, «Familia e igualdad de los sexos en el Estado constitucional: una mirada crítica al caso alemán», Revista de la Facultad de Derecho de la Universidad de Granada. El Derecho y la familia, 3 ffi época, num. 4, 200I, págs. 3II SS
} 
Rousseau: «Convengamos, pues, en que la fuerza no hace el derecho, y que no estamos obligados a obedecer más que a los poderes legítimos» ${ }^{25}$.

Esta cuestión se intenta resolver desde el Estado social que se empieza a implantar después de la segunda guerra mundial; un estado más ligado a la persona y que tiene como objetivo la consecución de la igualdad real, lo que supone trascender del plano formal de la ley, es decir de la igualdad en la ley y la igualdad en la aplicación de la ley, para alcanzar la igualdad social de todas las personas y de los colectivos en los que se inserta, como señala el artículo 9 de nuestra Constitución.

Ello significa, como se especifica en dicho artículo, que los poderes públicos han de desplegar políticas que remuevan los obstáculos que impidan o dificulten la plenitud de los derechos de igualdad y libertad, y facilitar la participación de todos los ciudadanos y ciudadanas en la vida política, económica, cultural y social; pero, sobre todo, implica que el Estado debe asumir un protagonismo activo en la transformación de las condiciones de vida que lleve a una sociedad más justa e igualitaria. Así pues, el desencuentro entre la igualdad formal y la desigualdad real se ha de resolver arbitrando medidas a favor de las personas y de los colectivos que están en una situación de inferioridad social. Se habla, en consecuencia, de adoptar políticas de acción positiva ${ }^{26}$ que suponen una quiebra de la igualdad formal, que se justifican por la consecución de la igualdad real y que tienen su fundamento en la diferente situación de partida en la que se encuentran personas y colectivos, entre los que están sin duda las mujeres ${ }^{27}$. A partir de ahí, se diseñan políticas dirigidas específicamente al género femenino, para propiciar su plena integración en la sociedad en condiciones de paridad con el varón ${ }^{28}$.

Sin embargo, lo que realmente supone este diferente planteamiento respecto al principio de igualdad es la quiebra definitiva de la uniformidad del sujeto de derechos, es decir del destinatario de la norma, que durante mucho tiempo había dominado la acción de los poderes públicos y, más en concreto, la producción normativa. Así, al hombre burgués que inicialmente había capitalizado la noción de ciudadano, hasta el punto de diseñar un modelo de relaciones que respondiera a sus aspiraciones e intereses, le habían surgido ya otros sujetos impuestos por los movimientos sociales, como fueron el trabajador o el campesino, que se convirtieron en actores de unas políticas y de una legislación netamente protectoras; a ellos le siguieron por imperativo del Estado social otros tantos sujetos. Se produjo entonces la quiebra del ciudadano único, pero ésta se resolvía en una clave eminentemente masculina, pues estos últimos eran también encarnaciones abstractas de una subjetividad social que todavía no diferenciaba hombres y mujeres. Cuando la implantación del Estado social lleva a reparar también en la situación de desigualdad de las mujeres, emerge entonces una normativa con un perfil muy diferente. Ya no se trata, como se ha dicho, de proclamar la igualdad de derechos entre unos y otras, ni de exigir que ambos fueran iguales en la aplicación de la ley; se trata de impedir que la situación de desventaja social en la que se encuentran las mujeres suponga un obstáculo para la igualdad que proclaman las leyes. Con ello, la dialéctica igualdad-desigualdad adquiere una nueva dimensión, pues la misma ya no se desenvuelve entre individuos de clases sociales diferentes, como la que se da entre el empresario y el trabajador, o en situaciones económicas dispares, como la que tiene el agricultor respecto a los otros empresarios; esta

\footnotetext{
${ }^{25}$ El contrato social cit. pág. 37 .

${ }^{26}$ «Mujer e igualdad: el ordenamiento constitucional; logros y posibilidades», Ruth Rubio Marín (coordinadora), Mujer e igualdad: la norma y su aplicación, Instituto Andaluz de la Mujer, Sevilla I999, pág. II.

${ }^{27}$ Sobre este tipo de medidas, Fátima Arranz, «algunas notas tecnológicas sobre los planes de igualdad de oportunidades en el marco de las políticas públicas dirigidas hacia las mujeres: el caso español», en Las políticas públicas en favor de las mujeres cit. págs. 36 ss.

${ }^{28}$ Una interesante exposición de las diferentes teorías feministas sobre el papel del Estado en la construcción de la ciudadanía de las mujeres, en Fátima Arranz, Introducción a Las políticas públicas a favor de las mujeres, cit. págs. $26 \mathrm{ss}$.
} 
dialéctica se da entre géneros, el femenino y el masculino, y ambos están presentes en todo el espectro social. Ello no es óbice para que determinadas medidas se adopten respecto a un conjunto de mujeres que se encuentran en una situación económica o laboral que requieren de una protección específica.

Así, surgen iniciativas políticas de apoyo y promoción de las mujeres que se nuclean en torno a instituciones $u$ organismos dedicados específicamente a ellas ${ }^{29}$ para propiciar su integración en todos los ámbitos de la sociedad. También se genera una normativa dirigida a facilitar su incorporación a la actividad profesional o laboral, mediante la conciliación de la vida familiar y laboral ${ }^{30}$. Ocurre, sin embargo, que la mujer empieza a depender del Estado y de las políticas públicas, hasta el punto de que su conquistada presencia en la sociedad sólo se asegura mediante la continua implicación de los poderes públicos, pues las bases en las que se asienta la organización social están lejos de cambiar; por ello se ha hablado, con acierto, de su maridaje con el Estado social ${ }^{31}$.

En el plano internacional también va adquiriendo relevancia la posición de la mujer que se refleja en los diferentes instrumentos internacionales que se pronuncian sobre su situación y sus derechos, si bien este reconocimiento se desenvuelve en un plano más teórico que real, como se pone de manifiesto en las alarmantes cifras de los informes del PNUD. No obstante, se debe reconocer el avance que ha significado los diferentes Acuerdos de las $\mathrm{NNUU}^{32}$, o las declaraciones internacionales que se han redactado después de las Conferencias Internacionales sobre la mujer ${ }^{33}$.

También se ha producido un cambio relevante en el discurso social, al menos en los países que se integran en la órbita de la cultura occidental, pues «La misoginia explícita y declarada hace tiempo que es políticamente incorrecta y, salvo raras excepciones, ha desaparecido del mundo académico y supuestamente culto» ${ }^{34}$.

Se consagra así la diversidad como patrón de la acción positiva del Estado, pero la igualdad real entre mujeres y hombres no acaba de cuajar, como se pone de manifiesto a través de diferentes indicadores que reflejan la posición de desventaja social de las primeras.

\section{La igualdad que no llega}

Las declaraciones constitucionales, las acciones de los poderes públicos, se han revelado hasta ahora insuficientes para invertir una realidad que aún se asienta en la

${ }^{29}$ En España se crean los Institutos de la mujer, al nivel estatal y autonómico, al mismo tiempo que casi todos los Ayuntamientos cuentan con una concejalía sobre la mujer, y desde esas instancias se han impulsado diferentes planes sobre igualdad de oportunidades entre mujeres y hombres. Judith Astelarra reflexiona sobre «Políticas públicas de igualdad de oportunidades», En torno al mercado de trabajo y las políticas de igualdad de oportunidades en España cit. págs. I33 ss.

${ }^{30}$ En España, Ley 39/1999, de 5 de noviembre de Conciliación de la vida familiar y laboral de las personas trabajadoras.

${ }^{31}$ Desde esta teoría se ha llegado a afirmar que las mujeres son el Welfare State, pues al mismo tiempo que son proveedoras de servicios son beneficiarias de los mismos, de tal manera que el Estado se convierte en una especie de «marido», «Maternidad, familia y Estado», Françoise Thebaud, Historia de las mujeres. El siglo XX (Roma I992), Madrid I993, pág. 455.

${ }^{32}$ Convención sobre la eliminación de todas las formas de discriminación contra las mujeres.

${ }^{33}$ Muy significativa fue la IV Conferencia Internacional sobre la Mujer celebrado en Bijing (China) en septiembre de I995.

${ }^{34}$ Victoria Camps atribuye este avance a los colectivos dedicados a los estudios de la mujer, «El papel social de la mujer en los últimos 25 años», www.fundacionsantamaria.org/mujer.htm. 
desigualdad real de las mujeres respecto a los hombres ${ }^{35}$. Así, podemos comprobar que a pesar de que se ha producido un sensible aumento del número de mujeres que han accedido a la formación y a la actividad profesional, las tasas de desempleo son más altas en el colectivo de las mujeres y ocurre, además, que cuando accede al trabajo, su remuneración es menor a la del hombre a igual actividad laboral; también es evidente su presencia más reducida en los puestos de trabajo de mayor cualificación, siendo en algunos casos especialmente significativa. Con frecuencia comprobamos que determinadas actividades laborales de baja cualificación están muy feminizadas, con lo que resulta fácil enmascarar una menor retribución económica de las mismas en razón del $\operatorname{sexo}^{36}$. Como pone de manifiesto Susana Brunel, la situación de las mujeres en el mercado laboral se caracteriza por una serie de variables que constatan la discriminación por razón de sexo: baja tasa de actividad y alta tasa de desempleo en relación con la masculina, segregación ocupacional, desigual retribución por trabajos de igual valor, mayor precariedad en la contratación, menor protección social y adjudicación casi en exclusiva de las responsabilidades familiares. ${ }^{37}$ Y precisamente esta situación de precariedad que tienen las mujeres en el mercado de trabajo es uno de los factores que explican el fenómeno que se ha dado en llamar la feminización de la pobreza. ${ }^{38}$

Y esta incorporación de la mujer a la actividad laboral, profesional, empresarial o formativa se ha realizado sin que se le haya aliviado del cumplimiento de las funciones familiares que le fueron asignadas, es decir, sin que se haya producido una asunción por parte de los hombres de las tareas de la casa y el cuidado de los hijos; y esta situación provoca que las mujeres trabajadoras, empresarias o profesionales, en definitiva aquellas que realizan una actividad social, deban soportar lo que se conoce como la doble jornada: la que tienen que desempeñar en su actividad exterior y la que tienen que realizar en el hogar. Esta situación que por sí misma es injusta, en la medida que hace recaer sobre la mujer el peso de la familia además de sus responsabilidades laborales, tiene también otras consecuencias respecto a su comportamiento. Una de ellas es sin duda el descenso de la natalidad hasta índices tan bajos que coloca a la mujer española la primera del mundo en este parámetro ${ }^{39}$; también ocurre que el matrimonio o la constitución de una pareja se produce a una edad más tardía por tener que compatibilizarlo con su formación o con la realización de una actividad profesional o laboral. Todo ello sin contar con las dificultades con las que se encuentran las mujeres que están en condiciones de tener descendencia para poder acceder a un puesto de trabajo, a las que se las sitúa en la difícil disyuntiva de tener que elegir entre la opción personal de ser madre o de constituir una familia y su acceso o promoción en el mundo del trabajo.

Y ante este panorama, la familia, que se había diseñado conforme a un reparto de roles entre el hombre y la mujer, se resiente con el cambio sin que se le den otras opciones de organización interna. En consecuencia, no se puede decir que la familia está en crisis, pues lo único que está en crisis es un modelo concreto que se impone en un determinado

\footnotetext{
${ }^{35}$ Victoria Camps concreta las causas de la desigualdad de las mujeres en la duplicidad del trabajo, la insuficiente igualdad de oportunidades y la condición «objetual» de la mujer, visible en las situaciones más extremas de violencia sexual, El siglo de las mujeres, Madrid ı998, pág. I6.

${ }^{36}$ Sobre el tema, Fatima Arranz, en la Introducción a Las políticas públicas a favor de las mujeres, Madrid 2002, págs. I9 y 20. Paloma de Villota e Ignacio Ferrari Herrero, «Sobre la desigual remuneración entre mujeres y hombres percibida a través de las estadísticas fiscales», En torno al mercado de trabajo y las políticas de igualdad de oportunidades en España cit. págs. 37 ss. En la misma obra, Laura de Pablos Escobar, «Desigualdad laboral desde la perspectiva de género», págs. 73 ss.

37 «Las mujeres en el mercado laboral en España», En torno al Mercado de Trabajo y las Políticas de Igualdad de Oportunidades, cit. pág. 99.

${ }^{38}$ Laura De Pablos Escobar, «Desigualdad laboral desde la perspectiva de género», En torno al Mercado de Trabajo y las Políticas de Igualdad de Oportunidades, cit. págs. 73 ss.

${ }^{39}$ La fecundidad ha caído de un 2,8 en el año I975 hasta un I,3 en el año 2002, La sociedad española tras 25 años de Constitución, INE, Madrid 2003.
} 
momento histórico, que cuando se alteran las bases en las que se asienta pone de manifiesto su injusticia intrínseca.

Precisamente, esa injusticia intrínseca a la que hemos aludido ha provocado que resulte dolorosamente alarmante el alto precio que las mujeres están pagando por su libertad personal, y que se refleja en el gran número de casos de malos tratos que padecen y en las muertes que se están produciendo a manos del varón con el que mantienen o han mantenido una relación sentimental, de noviazgo, matrimonio o simple convivencia, quien, desde su posición de poder, no acepta el ejercicio de la libertad personal de su pareja..$^{\circ}$

Rousseau: «El más fuerte no es nunca lo bastante fuerte para ser siempre el amo, si no transforma su fuerza en derecho y la obediencia en deber. De aquí el derecho del más fuerte; derecho tomado irónicamente en apariencia, y realmente establecido en principio.» ${ }^{4 \mathrm{I}}$

Y hasta tal punto ello es así, que podemos afirmar que la conquista por parte de la mujer de un sitio en la sociedad en iguales condiciones que el hombre se ha hecho en gran medida a costa de ella misma, de su trabajo, de sus renuncias, de su integridad física y de su propia vida.

Ahora bien, las mujeres que se dedican en exclusiva al cuidado de la familia, tampoco se encuentran en una situación más favorable, pues resulta que sobre las mismas recae la responsabilidad y la dedicación al cuidado y atención de los más necesitados, de los hijos menores y de los padres mayores, de los discapacitados y de los enfermos, con lo que están asumiendo en gran medida unas funciones que corresponden al conjunto de la sociedad, si no al mismo Estado, sin ningún tipo de reconocimiento y sin ninguna compensación económica ${ }^{42}$.

Y esta situación en la que se ha colocado a las mujeres, tanto las trabajadoras como a las que se les identifica como amas de casa, existe a pesar de las formulaciones constitucionales sobre la igualdad de los sexos; y a pesar, también, de la definición del Estado social y el compromiso de los poderes públicos con la igualdad real. Se podría argumentar que asistimos a un periodo transitorio que terminará con la definitiva implantación de la sociedad del bienestar, de tal suerte que las condiciones irán cambiando a medida que surtan efectos las políticas sociales diseñadas en apoyo a la mujer. Esta afirmación podría servir para países, como España, en los que todavía ha tenido un escaso desarrollo el Estado social. Sin embargo no se puede mantener si tiene en cuenta la experiencia de las sociedades más avanzadas, que tras décadas de políticas públicas a favor de la igualdad de los sexos, aún no han llegado a una plena equiparación entre hombres y mujeres $^{43}$. Y es que El Estado social no ha llegado a hacer las cuentas con el Estado liberal, del que sigue siendo subsidiario, como afirma Angel López: «El viejo sujeto abstracto y

\footnotetext{
${ }^{40}$ Cristina Garaizabal señala que la violencia de género es en última instancia una cuestión de poder que esta sociedad otorga a los hombres, «La violencia sexista», en Las políticas públicas en favor de las mujeres, cit. pág. 52. Respecto a España, las cifras son muy alarmantes: en el año 2003 se registró más de 50.000 denuncias de malos tratos, aumentando la violencia doméstica en un 16\%; en ese mismo año murieron 70 mujeres a manos de su pareja, un 34\% más que el año anterior. Fuente: Ministerio del interior e Instituto de la Mujer.

${ }^{41}$ El contrato social cit. pág. 36.

${ }^{42}$ Cristina Carrasco y Maribel Mayordomo critican las categorías utilizadas por las Encuestas de Población Activa que esconden un sesgo androcéntrico, entre otras razones porque hace invisible el trabajo de la mujer en la casa, «Mujeres, trabajo y actividad: La cara oculta de la EPA», en Paloma de Villota (coord.) En torno al mercado de trabajo y las políticas públicas de igualdad de oportunidades en España, Madrid 2000, págs. 2I Ss.

${ }^{43}$ El feminismo de los años ochenta, desde sus diferentes perspectivas, parte de una misma pregunta: Qué sucede para que las mujeres permanezcan discriminadas de la vida pública, aún en las sociedades más avanzadas, Fátima Herranz, Las políticas públicas a favor de las mujeres, cit. pág. 22.
} 
formalmente igual del fuerte Estado Liberal, solo en algún caso ha cedido su puesto al sujeto parcialmente concreto y sustancialmente igual del débil Estado Social» ${ }^{44}$.

Respecto a las mujeres, creemos que hay otra razón que explica la situación actual; nos referimos al hecho que la vida pública, es decir la que representa la actividad laboral, profesional, económica, política o cultural, responde a un diseño masculino que le da al hombre una preeminencia difícil de superar. Y entendemos que el diseño es masculino, no solo porque lo ha realizado el varón como protagonista indiscutible del ámbito de lo público, sino porque responde a su posición netamente diferenciada de la otra gran realidad que integra la sociedad en su conjunto: nos referimos a la familia, lo privado o lo domestico, como se quiera llamar. Refleja pues una visión parcial de un mundo que se ordena conforme a un solo patrón: el empresario, el trabajador, el profesional, el político, el economista, el artista...y que masculiniza a la mujer cuando decide asumir dichos roles, encontrando así una vía rápida para superar la exclusión en la que se encontraba. ${ }^{45}$

\section{La propuesta del contrato social mujeres hombres}

\section{I Fundamentos del Pacto: la desigualdad y la diversidad}

Como ya ocurriera históricamente, cuando mediante un contrato social se dio vida a un nuevo orden político asentado en la soberanía del pueblo, se debe proceder ahora a la celebración de un nuevo contrato social por el que se proceda a la refundación de la democracia que conocemos, que de ciudadanos pase a ser de ciudadanos y ciudadanas, o expresado en otros términos, de mujeres y hombres.

Se pretende en consecuencia volver, como ya explicara Rousseau, al momento inicial de constitución de la sociedad, al contrato originario, para restablecer las bases en las cuales se ha de asentar.

Rousseau: «Antes, pues, de examinar el acto por el cual un pueblo elige un rey, convendría examinar el acto por el cual un pueblo es un pueblo. Pues siendo este acto superior al otro, es el verdadero fundamento de la sociedad.» ${ }^{46}$

Unas bases que no pueden definirse desde la abstracción y desde la uniformidad, sino que han de partir de una realidad heterogénea para construir desde la diversidad la igualdad real de las mujeres y de los hombres ${ }^{47}$.

Rousseau: «Encontrar una forma de asociación que defienda y proteja con toda la fuerza común la persona y los bienes de cada asociado, y por la cual, uniéndose cada uno a todos, no obedezca, sin embargo, más que a sí mismo y permanezca tan libre como antes. Tal es el problema fundamental, cuya solución da el contrato social.» ${ }^{4}$

Por ello, el acto fundacional ha de ser el resultado de una convención en la que participen todas y todos, en cuanto personas y en cuanto género, pues lo que se pretende es un contrato entre partes situadas socialmente en posiciones diferentes, que con el diálogo y

${ }^{44}$ «Estado social y sujeto privado. Una reflexión finisecular», Quaderni Fiorentini per la storia del pensiero giudirico moderno, I996, pág. 459.

${ }^{45}$ Victoria Camps, El siglo de las mujeres, cit. pág. I6.

${ }^{46}$ De cómo hay que darse siempre la primera convención, El contrato social cit. pág. 43.

${ }^{47}$ Interesantes reflexiones de Celia Amorós acerca de la virtualidad del sujeto universal. Cifra el fracaso de la ilustración en que la universalidad del sujeto no se llevó hasta sus últimas consecuencias, por lo que no deben crearse más sujetos sino hacer posible el sujeto universal, Tiempo de feminismo cit. págs. 358 ss.

${ }^{48}$ El contrato social, cit pág. 44. 
el acuerdo han de construir una sociedad en la que se den las condiciones para la igualdad real de unas y otros. En la medida que hablamos de contrato, éste no puede ser el resultado de una acción unilateral, tampoco de la imposición de una parte a otra de unas reglas de comportamiento, sino que ha de responder a un acuerdo común de ambas partes que, desde su diferente posición, alcanzan un objetivo compartido, fijando las reglas de juego. No estamos ante una claudicación, ni ante una imposición, sino ante un contrato libremente formado.

Rousseau: «Por la misma razón que la soberanía es inalienable, es indivisible, pues la voluntad es general o no lo es; es la del cuerpo del pueblo o solamente la de una parte. En el primer caso, esa voluntad declarada es un acto de soberanía y hace ley. En el segundo caso, no es más que una voluntad particular, o un acto de magistratura; es, a lo sumo, un decreto» ${ }^{49}$.

Se requiere en primer lugar que ambos géneros actúen desde su libertad, es decir que las condiciones de inferioridad en la que socialmente puedan estar no supongan un obstáculo para aceptar o asumir un modelo que no se quiere, o para imponer desde la supremacía un orden social que excluya a la otra parte. En definitiva, consiste en darle una dimensión política a los asuntos que anteriormente se resolvían en el ámbito de lo privado; el feminismo, como afirma Celia Amorós, es político ${ }^{50}$.

Rousseau: «En el mismo instante, en lugar de la persona particular de cada contratante, este acto de asociación produce un cuerpo y colectivo compuesto de tantos miembros como votos tienen su asamblea, el cual recibe de este mismo acto su unidad, su yo común, su vida y su voluntad. Esta persona pública que se forma así, por la unión de todas las demás, tomaba en otro tiempo el nombre de Ciudad, y toma ahora el de República o el de cuerpo político, al cual llaman sus miembros Estado cuando es pasivo, Soberano cuando es activo, Poder cuando lo comparan con otro de su misma especie». ${ }^{5 \mathrm{r}}$

En este sentido, el contrato ha de suponer algo más que la mera constatación de la diversidad, ha de partir del reconocimiento de la desigualdad que en el plano de la realidad están muchas mujeres, hasta el punto de poder identificarlas con un colectivo desfavorecido, el que representa el género femenino. Supone en definitiva reconocer que existen notables diferencias entre mujeres y hombres en cuanto a su posición en la sociedad; consecuencia de una construcción de la desigualdad, más acentuada, paradójicamente, en la contemporaneidad, con la implantación del modelo burgués de separación de los espacios. Unas mujeres que se pueden encontrar en situaciones muy diversas, como es el caso de las que no han accedido al mundo del trabajo, o de las que son responsables de una familia monoparental, o de las trabajadoras de baja cualificación, o de las escasamente formadas; unas mujeres, en definitiva, que padecen la doble discriminación, la que se deriva de las condiciones en las que viven y la que tiene su origen en el sexo, pues, por encima de esta diversidad de situaciones en las que se pueden encontrar, y que supone para las mismas en muchos casos un agravamiento de la situación de desventaja, padecen una manifiesta discriminación por su condición de mujer.

Este contrato social ha de tener una dimensión horizontal. No se trata de pactar con un poder constituido un conjunto de medidas que mejore la situación, pues ello ha ocurrido con el Estado social. Se trata por el contrario de pactar las bases en las cuales se ha de asentar un nuevo orden político y social mediante unas reglas que lleven a una distribución diferente de los distintos espacios privados y públicos; en definitiva, a una refundación del sistema democrático.

\footnotetext{
${ }^{49}$ El contrato social cit. pág. 54 .

${ }^{50}$ En la obra de que es editora, Feminismo y Filosofía, Madrid, 2000, pág. I2.

${ }^{51}$ El contrato social cit. págs. 45 y 46.
} 


\subsection{Lo privado y lo público: una responsabilidad compartida}

Tal como se ha indicado, la plena integración de la mujer en la sociedad a la que pertenece requiere una profunda transformación de las reglas que rigen la organización social y sus pautas de comportamiento. Hasta ahora, éstas giraban en torno a dos mundos que funcionaban con cierta independencia: el mundo de lo privado, representado por la familia en el que estaba recluida la mujer, y el mundo de lo público, que pertenecía al hombre; y en ambos hasta hace poco dominaba el varón. Había pues una distribución de roles sobre la que se asentaba el funcionamiento de la sociedad en su conjunto: la familia era responsabilidad de la madre, esposa, hija o hermana, que debían asumir, según las circunstancias, las tareas del hogar y el cuidado de los más necesitados, fueran éstos los hijos menores, los padres mayores, los enfermos o los parientes necesitados. La actividad pública recaía casi en exclusiva en el hombre que, desligado de un compromiso familiar, podía entregarse plenamente a la misma ${ }^{52}$.

Ocurre que cuando la mujer decide de forma mayoritaria «salir del hogar» para participar en igualdad de condiciones que el hombre en los asuntos públicos, es decir en el trabajo, en la actividad social, cultural, política o económica, empieza a asumir con el varón la responsabilidad en estos ámbitos, pero no se da el fenómeno inverso de que el hombre participe en la vida familiar en igualdad de condiciones que la mujer y asuma su cuota de responsabilidad en la misma, con lo que se llega a la situación ya expuesta.

Pero aún hay más; esta dicotomía en torno a la cual se ordena el conjunto de las relaciones sociales refleja una distinta ponderación de lo publico y de lo privado, que se pone de manifiesto en la mayor relevancia de lo primero respecto a lo segundo.

En efecto, «plantear el trabajo familiar y el trabajo asalariado como un problema de estrategias femeninas de conciliación de tiempos significa, por una parte, seguir aceptándolo como una cuestión personal, privada y específica de las mujeres y, por otra, no reconocer que es absolutamente imposible que la mayoría de las mujeres se incorporen al mercado laboral de la forma en que lo hace la población masculina» ${ }^{53}$.

Por esta razón, se ha de partir de una afirmación inicial acerca de la relevancia que para el destino de cualquier sociedad tiene lo que ocurra en el ámbito familiar, que no es más que reconocer la trascendencia que en la organización social ha tenido y tiene la familia, que ha cumplido importantes funciones tanto respecto de los miembros que la integran como para el conjunto de la comunidad. La experiencia de la historia nos pone de manifiesto que la familia ha sido un tipo de organización presente en toda sociedad a cuyo desarrollo ha contribuido en muy distintos planos y en aspectos muy diferentes. La familia ha sido un medio privilegiado para la transmisión de los valores, ideas, reglas de comportamiento, hasta poder afirmar que constituye el ámbito más idóneo para la reproducción social del modelo que se quiere; también constituye un instrumento muy valioso para la cohesión social con la ayuda y atención que presta a los más necesitados, que no ha sido en ningún momento sustituida plenamente por los poderes públicos, ni con la implantación del régimen socialista, ni con el desarrollo del Estado social. La familia, igualmente, ha contribuido al desarrollo económico del Estado aportando su propia organización, en forma de unidad de producción agrícola, como empresa familiar, o como unidad en la manufactura de bienes. En otro plano se ha de tener en cuenta que es esencialmente en el seno de la familia donde reside la procreación, y también en la que se

\footnotetext{
${ }^{2}$ El feminismo de los años 60 acuñó la frase de «lo personal es político» para señalar la necesidad de modificar los patrones de comportamiento en éste ámbito y su interés para los poderes públicos; sobre el tema Cristina Sánchez Muñoz, «Feminismo liberal, radical y socialista», Feminismos. Debates teóricos contemporáneos cit. págs. 75 ss.

${ }^{53}$ Cristina Carrasco y Maribel Mayordomo, «Mujeres, trabajos y actividad: La cara oculta de la EPA», cit. pág. 35.
} 
produce el proceso de socialización de las niñas y de los niños. Y en todas estas funciones que históricamente ha cumplido la familia y que en una gran medida sigue desempeñando en la actualidad, el papel de la mujer ha sido imprescindible precisamente por su dedicación casi en exclusiva a la familia.

La importancia de la familia también se refleja en nuestro texto constitucional que en su artículo 39 recoge en compromiso de los poderes públicos de protegerla en el plano social, económico y jurídico ${ }^{54}$. Dicho artículo supone algo más que el reconocimiento del hecho social de la existencia de la familia: implica asegurar su mantenimiento mediante la protección adecuada.

En consecuencia, no se puede defender la preferencia de lo público, en los términos en los que lo estamos entendiendo, frente a la familia; tampoco se debe mantener que ésta es responsabilidad de la mujer, pues tal posición, además de chocar frontalmente con los derechos constitucionalmente reconocidos como la igualdad o la libertad, supone dejar a la deriva la familia cuando la mujer no puede dedicarle la atención suficiente.

Sin embargo, no podemos caer en una plena identificación de lo privado con la familia, pues a dicho ámbito también pertenece el desarrollo de la personalidad, el establecimiento de relaciones afectivas, la realización de las aspiraciones personales, la dimensión cultural de la persona, en definitiva el desenvolvimiento de las capacidades que como ser humano se tienen y que en ningún caso se agotan en la actividad laboral o profesional.

Se requiere pues que se atienda y valore en los mismos términos los que antaño fueron consagrados como espacios diferenciados y disímiles.

Una vez dicho esto, se ha de caminar en dos sentidos paralelos: la corresponsabilidad de la mujer y el hombre respecto a la familia y la compatibilidad de ambos mundos.

Cuando se habla de corresponsabilidad, se quiere aludir a la necesidad de que tanto la mujer como el hombre en las distintas condiciones que se pueden encontrar en el seno de la familia, es decir como cónyuge, como compañero o compañera, como madre o padre, como hija o hijo...deben asumir sus cometidos con la misma intensidad y contenido. Ello resulta más evidente en las relaciones de pareja y en el ejercicio de la patria potestad, pues el tipo de relaciones que se establece exige una mayor dedicación de la mujer y del hombre.

Y solamente desde esta perspectiva se debe abordar la regulación sobre la compatibilidad de la vida familiar y laboral ${ }^{55}$ y cualquier otra medida que se adopte en el sentido de facilitar la incorporación de la mujer a la actividad laboral. Ahora bien, para la efectividad de las mismas se requiere partir de la constatación de un hecho, el que todavía son las mujeres en cuanto madres y esposas las que están asumiendo en mayor proporción el cuidado y la atención a la familia, pues solamente reconociendo la realidad se pueden desplegar políticas que corrijan la situación e inviertan la tendencia aún existente de identificar la familia con la mujer. En efecto, no basta que se reconozca la posibilidad de

\footnotetext{
${ }^{54}$ Art. 39 CE: «I. Los poderes públicos aseguran la protección social, económica y jurídica de la familia. 2. Los poderes públicos aseguran asimismo la protección integral de los hijos, iguales éstos ante la ley con independencia de su filiación, y de las madres, cualquiera que sea su estado civil. La ley posibilitará la investigación de la paternidad. 2. Los padres deben prestar asistencia de todo orden a los hijos habidos dentro y fuera del matrimonio, durante su minoría de edad y en los demás casos que legalmente proceda. 4. Los niños gozarán de la protección prevista en los acuerdos internacionales que velan por sus derechos.»

${ }^{55}$ Una propuesta, la del sindicato UGT, la recoge Carmen García Cruz, «El empleo de las mujeres», En torno al mercado de trabajo y la política de igualdad de oportunidades en España cit. págs. II3. En la misma obra Lucila Gómez-Baeza Tinturé, «las mujeres y el empleo», págs. I23 ss.
} 
elegir por parte de la madre o del padre el disfrute de determinado beneficio para el cuidado de los hijos, pues posiblemente tal como están las cosas sea la madre la que ejerza en la mayoría de los casos esta opción; sino impulsar al padre a que también se decida por la atención a los hijos. Desde esta perspectiva son cuestionables las medidas de carácter generalizador que se dirigen a la madre trabajadora, pues inciden en la tendencia expuesta de atribuirle preferentemente la función de educarlos y cuidarlos, y confirman la identificación de los hijos con la madre; pudiéndose dar el caso, incluso, de inducir comportamientos contrarios a la lógica emancipadora: en el supuesto de ruptura de la convivencia de los padres, que se opte porque los hijos comunes se queden con la madre para así poder beneficiarse de las prestaciones que a ella se dirigen. Distinto es que en determinadas situaciones en las que se compruebe que es la mujer la que tiene sobre sí la responsabilidad familiar, caso que ocurre en las familias monoparentales, se le destinen determinadas ayudas que le permitan responder a sus necesidades y acceder igualmente al mundo del trabajo. Si bien se debe tener en cuenta que la feminización de las familias monoparentales no es más que una consecuencia de la identificación preferente de la familia con la mujer, lo que lleva a que en la mayoría de los casos de ruptura de la relación de pareja sea ésta la que asuma el cuidado de los hijos.

Estamos hablando, en consecuencia, de la necesidad de que se elaboren políticas que lleven a una corresponsabilidad efectiva de las mujeres y de los hombres en el cuidado y la atención a la familia, y no de acciones concretas que únicamente faciliten el acceso de la esposa o madre al trabajo, suministrándole los medios para que le alivien las tareas.

Por ello, lo expuesto nos acerca a una reflexión de más calado, consistente en plantearse si no deben cambiar las reglas que rigen el funcionamiento de la sociedad para que se pueda dar una mayor compatibilidad entre la vida privada y la actividad pública. Ello supone cuestionarse la jornada laboral, su extensión y horario. También la ordenación de las ciudades, que no pueden seguir respondiendo a una neta separación de los espacios públicos y privados, tal como en su momento se diseñaran ${ }^{56}$; y en este sentido se debe reflexionar igualmente acerca de los servicios públicos, su ubicación, incluso sobre su contenido, es decir, las prestaciones que han de ofrecer a la familia en su conjunto, así como el tiempo durante el cual se realizan los servicios de atención. También deben responder a esta compatibilidad entre vida privada y pública la actividad comercial o la de los prestadores de servicios, para facilitar la adquisición de los bienes necesarios para la satisfacción de las necesidades y la utilización de los servicios en condiciones que no perjudiquen tanto una como otra esfera de la persona.

En definitiva, lo que se plantea es un debate acerca de la organización familiar y social en términos que permitan su compatibilidad, para que las decisiones que respecto a una y a otra deban tomar las mujeres y los hombres sean fruto de la libertad personal y no de las imposiciones.

\subsection{La paridad en la participación política.}

Una vez asentadas las bases de la corresponsabilidad y la compatibilidad, es necesario construir un poder político y un modelo de comportamiento social que asegure el resultado que se pretende, es decir la igualdad real de mujeres y hombres. Solo cuando éstos funcionen con criterios de paridad se estará en condiciones de que las normas que se generen, las decisiones que se adopten, las políticas que se desarrollen, o las medidas que se implementen tengan en cuenta la dispar situación en la que se encuentran las mujeres

\footnotetext{
${ }^{56}$ Una interesante reflexión en Amelia Valcarcel, La política de las mujeres cit. págs. I8I ss.
} 
respecto de los hombres y ofrezcan instrumentos eficaces con los que remover los obstáculos que impiden el pleno disfrute de sus derechos.

La primera cuestión a abordar es el diseño de cómo se ha de ejercer el poder dentro de la sociedad, un poder que, como afirma Amelia Valcarcel, denota masculinidad ${ }^{57}$.

Y aquí aparece la propuesta de elaborar un modelo en el que participen paritariamente las mujeres y los hombres; se trata de consagrar unas reglas de funcionamiento que aseguren la presencia igualitaria de los dos géneros en todos los centros de decisión sobre el destino de la sociedad. ${ }^{58}$

En efecto, la situación actual pone de manifiesto la escasa presencia de las mujeres en las diferentes instancias políticas, a nivel internacional, en el ámbito la UE, en el estatal, autonómico o local. También es manifiesta su limitada participación en otros centros de poder o decisión, como ocurre en la actividad jurisdiccional, en la profesional, en la académica, y también en lo económico, en las organizaciones sociales, o en la cultura, por poner algunos ejemplos.

Se han avanzado fórmulas para corregir esta situación, que se han concretado esencialmente en establecer criterios que aseguren o garanticen una presencia efectiva de las mujeres en las mismas condiciones que el hombre en todos los ámbitos de poder ${ }^{59}:$ «La teleología que persigue es la representación genérica, es decir, que las mujeres genéricamente tengan representación de poder y tal representación de poder incida sobre el sistema completo de captar el poder genéricamente, de ser captado, de ser visto o percibido» ${ }^{60}$. En el convencimiento de que, como expresa Marion Young, la representación de grupo es la mejor forma de promover resultados justos en los procesos democráticos de toma de decisiones ${ }^{6 \mathrm{I}}$.

Las propuestas en este sentido son variadas aunque todas parten de la misma idea: solo se puede corregir la desigual participación de la mujer si se incide en la situación de partida desde la que se conforman la composición de los órganos de poder; así, en lo que respecta a los órganos de representación parlamentaria, se ha insistido en la necesidad de que las candidaturas a los mismos se elaboren bien alternando la presencia de hombres y mujeres, de tal manera que la oferta inicial no pueda frustrarse en la consulta popular, lo que se conoce como la ley cremallera; o asegurar una composición en la que al menos cualquiera de los géneros tenga un cuarenta por ciento, por su posición en las candidaturas, que le permitan acceder al puesto de representación ${ }^{62}$. Frente a estas propuestas se siguen otras menos contundentes, podríamos decir, pues las mismas no se

\footnotetext{
${ }^{57}$ Esto es así, es un hecho innegable que no necesita mayores disquisiciones, Amelia Valcarcel, La política de las mujeres, cit. pág. I25.

${ }_{58}$ «La traducción del principio de igualdad al principio de discriminación positiva aboca a la exigencia de un sistema de cuota de participación en un poder dado», Amelia Valcarcel, La política de las mujeres cit. pág. IIo.

${ }^{59}$ Celia Amorós se pronuncia en contra de la democracia paritaria, sin embargo se muestra favorable a la existencia de cuotas para las mujeres en los partidos políticos, Tiempo de feminismo, cit. págs. 287 ss. Por su parte, Iris Marion Young propone el siguiente principio: «un sistema de gobierno republicano y democrático, independientemente de cómo se constituya, debería de proporcionar mecanismos para la representación y reconocimiento efectivo de las distintas voces y perspectivas de aquellos de sus grupos constituyentes que se encuentren en situación de desventaja u opresión», «Vida pública y diferencia de grupo», Carme Castell, Perspectivas feministas en teoría de género cit. pág. III.

60 Amelia Valcarcel, que también señala las dificultades que tiene esta propuesta, como es la pérdida de individualidad de la mujer hasta el punto de ser irrelevante la presencia de una u otra, La política de las mujeres, cit. pág. 126.

${ }^{61}$ «Vida política y diferencia de grupo», Carme Castell, Perspectivas feministas en teoría de género cit. pág. II3.

${ }^{62}$ Esta es la fórmula propuesta en la Cumbre Europea de Mujeres en el Poder celebrada en Atenas en I992. Un tratamiento del tema en Anne Phillips, «¿Deben abandonar las feministas la democracia liberal?, Carme Castell, Perspectivas feministas en teoría política cit. págs. 9I ss.
} 
imponen sino que únicamente incentivan, como ocurre en Francia, donde las subvenciones estatales a los partidos políticos se condicionan al objetivo de la paridad.

La exigencia de una composición paritaria de la representación política ha chocado con una determinada concepción del principio de igualdad formal, hasta el punto de considerar esta medida como una discriminación intolerable para la igualdad que consagran los textos constitucionales. En tal caso se está pensando en la igualdad formal y abstracta, que en su misma formulación resulta incompatible con cualquier tipo de discriminación, y no en la igualdad que se mide por su eficiencia en remover los obstáculos que impiden a las ciudadanas y ciudadanos el pleno ejercicio de sus derechos, pues si nos atenemos a ésta última, la paridad no es una contravención sino exigencia ${ }^{63}$. Hemos comprobado lo que ocurre con el principio de igualdad cuando se desconecta de la realidad concreta a la que tiene que aplicarse, que se convierte en relativo e incompleto, por lo que $\mathrm{su}$ entendimiento en esos términos no puede seguir siendo patrón para medir lo que sea la igualdad, pues como se ha afirmado, «esta abstracción, esta formalización del sujeto, no sólo oculta y elude las desigualdades y por tanto el conflicto real, sino lo que hace fundamentalmente es impedir que la desigualdad, el conflicto (que es intersubjetivo) se traslade al orden jurídico político. La configuración jurídico formal implica por tanto la mediación y superación a ese nivel del conflicto intersubjetivo». ${ }^{64}$

Hay que superar el doble lenguaje de la igualdad formal y la igualdad real hasta entender que solo habrá igualdad cuando en la realidad de los hechos las mujeres y los hombres se encuentren en la misma situación para decidir con libertad su propio destino. En consecuencia, la participación paritaria de hombres y mujeres en la representación y gobierno de los asuntos públicos refleja la efectiva composición de la sociedad y, lo que es más importante, sitúa a las mujeres como colectivo discriminado socialmente en las mismas condiciones que los hombres de decidir acerca de la sociedad que quieren.

Claro está que esta presencia en igualdad de condiciones no se ha de reducir exclusivamente a los órganos de representación política, sino que se ha extender a todas las instancias del Estado, si bien se debe tener en cuenta que en aquellas funciones que requieren unos específicos méritos profesionales o una determinada formación para su desempeño eficaz, es decir que rige por el principio de meritocracia la selección de sus miembros, no se puede sin más imponer criterios como los anteriores, por lo que se han de arbitrar mecanismos específicos que tiendan a la realización del principio de igualdad real.

Pero, sobre todo, a lo que nos debe llevar este planteamiento acerca de la paridad es a un repensar la democracia actual, en el sentido de que la misma tal como está concebida se manifiesta insuficiente para garantizar la plena participación de todas las mujeres y los hombres; estamos aludiendo a la democracia participativa como un grado más de evolución de esta democracia parlamentaria que actualmente tenemos ${ }^{65}$. En efecto, el control social acerca del gobierno de los asuntos públicos no se puede limitar al acto de la

\footnotetext{
${ }^{63}$ Un tratamiento de la virtualidad del principio de igualdad desde una perspectiva de género lo podemos encontrar en Ruth Rubio Marín que propone como criterio de aplicación la contextualización y la dimensión colectiva del fenómeno discriminatorio en la aplicación de la discriminación, «Mujer e igualdad: El ordenamiento constitucional, logros y posibilidades.», en Mujer e Igualdad: La norma y su aplicación, Instituto Andaluz de la Mujer, Sevilla I999, págs. I8 ss.

${ }^{64}$ Carlos de Cabo Martín, «El sujeto y sus derechos», cit. págs. I22 y I23.

${ }^{65}$ El movimiento feminista de los años sesenta y setenta compartió con los grupos radicales una visión de una democracia más activa y participativa; a partir de ello se identificó con los valores de la democracia local y descentralizada: con la idea de que la democracia debe estar presente siempre que existan relaciones de poder. Sin embargo hay una segunda fase de ese movimiento en el que se ha preocupado del macronivel de la pertenencia de las mujeres a la comunidad política, a explorar cuestiones de inclusión y exclusión y a amortiguar las pretensiones universalistas del pensamiento político moderno, Anne Phillips, «¿Deben las feministas abandonar la democracia liberal?», Carme Castell, Perspectivas feministas en teoría política, cit. págs. 79 y 80.
} 
votación de los representantes cuando se convocan a las urnas a los ciudadanos y ciudadanas; la experiencia histórica nos ha demostrado que durante el periodo de mandato de tales representantes o de los gobernantes se produce un alejamiento real de unos y otros, hasta el punto de llegar a un divorcio entre las aspiraciones reales de la ciudadanía y los actos de aquellos; un divorcio que difícilmente se puede superar en cada consulta popular. Hablar de democracia participativa supone superar esta concepción reduccionista de la democracia, entendida como gobierno del pueblo, para diseñar instrumentos, crear instancias, abrir cauces que permitan a los ciudadanos y ciudadanas exponer sus problemas, proponer soluciones y ejercer un control permanente del ejercicio del poder, de tal manera que el mismo responda a una participación real de sus destinatarios. Y ésta debería ser la gran aportación de los colectivos feministas a la construcción social, de aquellos que piensan que la incorporación de la mujer a los ámbitos públicos no es solo una cuestión de número, sino de transformación de las pautas sociales de comportamiento para poder alcanzar una igualdad real de todos los ciudadanos y ciudadanas y de los colectivos en los que se integran.

\subsection{La feminización de la sociedad}

Hasta ahora, la incorporación de las mujeres a la actividad pública ha exigido de las mismas una masculinización ${ }^{66}$ de sus comportamientos para que puedan adaptarse, sin merma de sus posibilidades, a las exigencias o requerimientos que se le plantean en el ámbito formativo, laboral, profesional, empresarial, social, político o cultural. Y este proceso ha tenido unas consecuencias inmediatas, como ya hemos tenido ocasión de exponer. Pero, sobre todo, ha representado para la mujer el que abdique de su propia condición para comportarse como varón. Y esta afirmación resulta más evidente, paradójicamente, para aquellas mujeres que han alcanzado el éxito social, es decir para las «mujeres liberadas», esa élite de privilegiadas que gozan de autonomía profesional y económica, (que) no han tenido más remedio que adoptar el modelo masculino de trabajo $y$ dominación ${ }^{67}$.

En consecuencia, una vez que se creen las condiciones, a las que hemos aludido en los párrafos anteriores, las mujeres, individualmente o como colectivo, podrán proyectar otra visión de la realidad o defender libremente un conjunto de valores, que esencialmente se nutren de una experiencia personal ligada muy directamente a su desarrollo intrínseco, y también de una trayectoria colectiva que es posible identificar con el mundo de lo privado en el que ha estado mayoritariamente inmersa. Desde esta perspectiva, la feminización es un resultado del proceso de transformación social que se pretende, y que se ha expuesto anteriormente. Serán pues las mujeres desde su libertad personal las que lleven a cabo esa feminización; el alcance de la misma así como su contenido se concretará cuando se implante el contrato social ${ }^{68}$.

Sin embargo, se puede ir más allá de la idea expuesta y entender que es posible apriorísticamente identificar un conjunto de valores, unas reglas de comportamientos como genuinamente femeninas, que hay que incorporar desde ya a la cosmovisión masculina que ha presidio hasta ahora la conformación de la sociedad, al entender que la lógica masculina supone un obstáculo para que las mujeres puedan asumir plenamente su protagonismo en la sociedad a la que pertenecen. La cuestión que se plantea tiene su complejidad. De

\footnotetext{
${ }^{66}$ Un interesante y variado tratamiento de la masculinidad en José María Valcuende del Rio y Juan Blanco López (editores) Hombres. La construcción cultural de las masculinidades, Madrid 2003.

${ }^{67}$ Victoria Camps, «El papel social de la mujer en los 25 últimos años», cit. pág. 2.

${ }^{68}$ A esta idea responde lo que se conoce como el feminismo liberal, sobre el mismo consultar Cristina Sanchez Muñoz, «El feminismo liberal», Feminismos. Debates teóricos contemporáneos cit. págs. 86 ss.
} 
entrada, significa que se reconoce a las mujeres un conjunto de valores, o una concepción acerca de la realidad que le rodea, diferente a la de los hombres, y ésta es una cuestión controvertida dentro del discurso feminista. Además, plantea el problema añadido del fundamento y la identificación de dicha feminidad.

Se puede argumentar igualmente que la determinación de valores, pautas de comportamientos o formas de organización como femeninas esconde una trampa: en la medida que la delimitación de lo privado ha sido una construcción eminentemente masculina así como la propia representación social de la mujer, se corre el riesgo de identificarla precisamente con la posición de la que quiere salir ${ }^{6}$. Es clásica en este sentido la frase de Simone de Beauvoir, «una mujer no nace, se hace».

A pesar de todo, y siendo conscientes de la trascendencia de la cuestión que se plantea, entendemos que es posible y también necesario la identificación, al menos, de otra forma de encarar los problemas que aquejan a la sociedad actual, que se corresponde con un ámbito muy determinado de la realidad social, el que representa lo privado, en el que los objetivos a conseguir, como la implicación de los miembros que lo integran, responden a una lógica de comportamiento muy diferente a la que ha presidido el ámbito de las relaciones sociales que se desarrollan en la esfera de lo público. Así, sin incurrir en un exceso de teorización que nos lleve a dogmatizar lo que son construcciones sociales, hasta el punto de dotarles de una trascendencia que supere la propia experiencia histórica, sí se puede identificar «lo femenino» desde una perspectiva empírica que atienda a la posición que hasta ahora han ocupado las mujeres en la sociedad, entendiendo en todo caso que nos encontramos ante procesos de construcción que evolucionan a impulsos de acontecimientos internos y externos. Como dice, Victoria Camps: hablar de valores masculinos y femeninos no tiene por qué significar la consagración de una dicotomía genérica avanzada por el llamado «feminismo de la diferencia». No se trata de mantener, como ese feminismo suele hacer, posturas esencialistas. Se trata, por el contrario, de apostar por una sociedad que acepte «otras formas de mirar»y, en consecuencia, otras formas de actuar ${ }^{70}$.

En este sentido, no creemos que la diferencia biológica implique una visión diferente del mundo que nos rodea ${ }^{7 \mathrm{I}}$, pero sí podemos comprobar que la mujer ha estado mayoritariamente inmersa en un mundo distinto al del varón, y que de ese mundo representado por la familia o por lo privado o lo doméstico se pueden extraer algunas valoraciones o reglas que no se identifican con las que dominan lo público, pues ambos obedecen a una lógica bien distinta; nos referimos, a lo que Victoria Camps identifica con la historia y la tradición compartida por las mujeres ${ }^{72}$. Desde esta perspectiva, cuando se habla de feminizar o de feminización, a lo que se hace referencia es a las representaciones que se han generado en el espacio privado acerca de la persona, sus aspiraciones, los valores que han de orientar su vida o las pautas que han de regir su comportamiento; y es la mujer, protagonista indiscutible de esa esfera de relaciones, la que los puede aportar. Lo mismo

${ }^{69}$ Las feministas han empleado en ocasiones un modelo de yo que parte de la posibilidad de distinguir entre un yo «interno», que es un yo femenino auténtico, y un yo «externo», que es el falso yo femenino, en Cristine Di Stefano, «Problemas e incomodidades a propósito de la autonomía: algunas consideraciones desde el feminismo», Carme Castell, Perspectivas feministas en teoría política cit. pág. 64 .

${ }^{70}$ El siglo de las mujeres, cit. pág. I6.

${ }^{71}$ Sin embargo, no se puede desconocer el hecho de la maternidad y las consecuencias que para los derechos laborales de las mujeres tiene; el problema, como señala Iris Marion Young, surge cuando la diferencia se convierte en desviación, estigma o desventaja, «Vida política y diferencia de grupo», Carme Castell, Perspectivas feministas en teoría política cit. pág. I2I.

${ }^{72}$ Como dice la autora, no se trata ni de quedarse en el pasado ni de aferrarse a él, tampoco se trata de hacer de la necesidad virtud, se trata por el contrario de aceptar que la historia y la tradición ha producido una especial manera de ser que, aunque haya sido servil durante años, se puede mantener superado este servilismo, Virtudes públicas, 3 ffi ed. Madrid i996, pág. I3I 
que cuando se alude a la masculinidad se quiere encarnar en el hombre lo que representa la esfera de lo público en contraposición a lo privado.

Así pues, avanzando en la idea de que hablar de feminización supone la aportación de lo privado a lo público, el reequilibrio que tiene que haber entre uno y otro aspecto tanto en la vida de las personas, como en la organización social que tratamos anteriormente, se ha de traducir en la exigencia de que el desarrollo de la personalidad o la realización de las capacidades y compromisos individuales, así como el desenvolvimiento de las relaciones familiares, tienen que tener un espacio equilibrado con el que protagonizan las actividades públicas, y que no se pueden convertir en el eje de la construcción individual y colectiva en perjuicio de un crecimiento interior que dignifique al ser humano. Lo dicho implica diseñar una organización social que refuerce el papel de la cultura, del ocio, o de las relaciones personales y familiares desde la libertad y la igualdad, para construir una sociedad de dimensión humana. Y esta idea se debe proyectar en la actividad productiva y demás actividades públicas, en la consideración del medio ambiente, en la determinación de las prioridades sociales; y también en el diseño de los espacios, sean éstos privados o públicos ${ }^{73}$. A partir de ahí, serán los hombres y mujeres los que construyan una sociedad que les pertenezca a todos y a todas por igual.

Cabe incluso profundizar más en esta idea y entender que se debe construir una subjetividad femenina, en el sentido de identificar a las mujeres como sujetos diferenciados. Como telón de fondo de esta propuesta está el debate de la universalidad del sujeto del derecho, del actor político o del ciudadano sobre el que gira el pensamiento político y filosófico de la modernidad, cuestionado por la llamada postmodernidad, que frente a la idea de un sujeto universal y uniforme opone la realidad de la diferencia; un debate en el que se involucran cuestiones de gran calado que afectan a los fundamentos del Estado democrático y en el que, que por razones evidentes, no vamos a entrar en este momento.

El tema que se plantea no es pacífico en el pensamiento feminista, que mantiene al respecto posiciones muy dispares ${ }^{74}$.

Sin entrar de nuevo en un debate cuya profundidad excede las pretensiones de estas páginas, si debemos apuntar algunas ideas al respecto. Y la primera de ellas es la insuficiencia de la formulación teórica de la abstracción del sujeto para resolver los problemas de determinados colectivos o grupos que están en una situación de desventaja social; como dice Amelia Valcarcel, «El individualismo a secas no es defendible», ${ }^{75}$ o como afirma Victoria Camps: «El error quizá estuvo en aspirar a lo universal sin más» ${ }^{76}$.

\footnotetext{
${ }^{73}$ Se habla así de una «ética de la justicia», que se caracteriza por abordar las cuestiones morales de una forma abstracta, deontológica, que ha sido considerada por muchas feministas como una forma de razonamiento moral masculinizante, a la que se opone la «ética del cuidado» que concibe a las personas como seres interdependientes y no independientes, lo que le lleva a sostener que la moralidad ha de ocuparse de las cuestiones relativas a la empatía y las relaciones personales, Carme Castell, Introducción a la obra de la que es compiladora, Perspectivas feministas en teoría política, Barcelona I996, pág. 20; sobre la ética feminista, Alison M. Jaggar, «Etica feminista: algunos temas para los años noventa», en la obra anterior, págs. I67 ss.

${ }^{74}$ Una exposición de las diferentes teorías en Elena Beltrán Pedreira, «Justicia, democracia y ciudadanía: las vías hacia la igualdad», Feminismos. Debates teóricos contemporáneos cit. págs. I9I ss.

${ }^{75}$ El siglo de las mujeres, cit. pág. I62.

${ }^{76} \mathrm{Y}$ continua, «Error que descansa en el supuesto de que somos esencialmente razón y de que esa razón, que es la misma para todos, señala el camino de la igualdad y de la libertad. En realidad es muy difícil hablar de la redención de las desigualdades y las injusticias sin detenerse antes en ellas, ver cuales son y cuales son sus causas», El siglo de las mujeres, Madrid, I998.
} 
Una vez constatada la ineficacia del modelo universal y abstracto para resolver con parámetros de igualdad real las diferentes situaciones de partida en la que la sociedad ha colocado a algunos colectivos, entre los que se encuentra sin duda el de las mujeres, queda por elaborar una noción de sujeto o sujetos que refleje la diversidad. Esta tarea se desenvuelve entre la aspiración por lo universal, en el sentido de extender a todos y a todas las conquistas que ha supuesto el modelo democrático, y la necesidad de reconocer y dar respuesta a las diferentes situaciones de partida en las han sido colocados los colectivos sociales y, más específicamente, las mujeres. Que este dilema se resuelva desde la uniformidad o desde la diversidad es la cuestión a la que se enfrenta la teoría y acción del feminismo actual ${ }^{77}$.

Las propuestas en este sentido son muy variadas y así, se apuesta, como hace Celia Amorós, por la defensa de un sujeto mínimo para hacer posible un proyecto de sociedad en la que pueda darse un sujeto máximo, entendiendo por tal, un sujeto con un nivel de autonomía y de capacidad crítico-reflexiva potenciado hasta el mayor grado dentro de lo que se pueda concebir como verosímil ${ }^{78}$. O se incide en la defensa de una ciudadanía diferenciada, como expresa Victoria Camps, que considera la perspectiva universalista, defendida por el primer feminismo esencialmente masculina ${ }^{79}$; o desde posiciones más radicales representadas por el feminismo de la diferencia, que apuesta por el abandono de cualquier pretensión de universalidad para optar por la diversidad ${ }^{80}$. Las posibilidades están abiertas en un debate intenso que no podemos considerar aún cerrado ni superado por otros planteamientos.

Lo cierto de todo ello es que la fuerza del pensamiento feminista, como la de la acción política de los colectivos de mujeres está poniendo en cuestión las bases en las que se asienta el modelo de organización política de la cultura occidental y que sus reflexiones, así como las demandas que plantean, cuestionan la tendencia de la universalización y la abstracción del sujeto hacia una uniformidad exclusivamente formal, ajena a la diversidad real de la sociedad, e incapaz de resolver los problemas específicos de las mujeres que se encuentran en una situación de desigualdad real para el disfrute de los derechos universales que se proclaman. Y lo que resulta aún más interesante, que las quiebras que se apuntan, que las interrogantes que se plantean, que las propuestas que se elaboran, no se circunscriben exclusivamente al género femenino sino que se extienden a los otros y a las otras, a los diversos, ofreciendo todo un mundo de posibilidades para que las personas y los colectivos en los que se integran puedan realizar plenamente sus derechos. Y en esta tarea inacabada pero ilusionante debemos empeñarnos todas y todos cuantos creemos que es posible la construcción de un mundo mejor.

77 Un exposición de las diferentes posiciones sobre el tema en Sivina Alvarez, «Diferencia y teoría feminista», Feminismos. Debates teóricos contemporáneos, cit. págs. 243.

${ }^{78}$ Tiempo de feminismo, cit. pág. 25.

${ }^{79}$ El siglo de las mujeres, cit. págs. 30 у 31.

${ }^{80}$ Este feminismo se inscribe dentro del discurso de la postmodernidad, que se identifica con el rechazo del universalismo racionalista, se identifica también con el antiesencialismo, refuta también la noción de sujeto como categoría universal y reivindica la idea de deconstrucción, Silvina Alvarez, «Diferencia y teoría feminista», Feminismos. Debates teóricos contemporáneos, cit. pág. 255. 